LETTER TO THE EDITOR

\title{
Mental health of older adults amid the COVID-19 pandemic in low and middle-income countries: the unseen epidemic
}

Saúde mental de idosos na pandemia COVID-19 em países de baixa e média renda: a epidemia invisível

La salud mental de los ancianos en la pandemia COVID-19 e los países de ingresos bajos y medianos: la epidemia invisible

Wyllians Vendramini Borelli $\mathbb{B}^{\text {a }}$

a Hospital de Clínicas de Porto Alegre, Departamento de Neurologia - Porto Alegre/RS - Brasil.

Instituição: Hospital de Clínicas de Porto Alegre, Departamento de Neurologia - Porto Alegre/RS - Brasil

DOI 10.5935/2318-0404.20210002

Abstract

Carta to the editor

Keywords: Aged; Suicide; Loneliness; Depression; Anxiety

\section{Resumo}

Carta ao editor

Palavras-chaves: Idoso; Suicídio; Solidão; Depressão; Ansiedade

\section{Resumen}

Carta al editor

Palabras clave: Anciano; Suicidio; Soledad; Depresión; Ansiedad 
Older adults are the most vulnerable population affected by the Coronavirus-disease (COVID-19) pandemic ${ }^{1}$. There is an increasing number of studies focused on the mental health of older adults and potential strategies for the pandemic. However, low- and middle-income countries exhibit particularities that must be addressed to provide efficient measures to reduce the negative impacts of the pandemic in mental health of older adults.

A myriad of psychological symptoms was described in older adults amid the pandemic. Social isolation has increased the feeling of loneliness in older adults, which was previously described as a major concern for the well-being in the elderly². Psychological distress, namely depression and anxiety, is often present in socially distant older adults, and massively increased during the quarantine. There is also increasing evidence for the risk of suicide among this population, which is often underestimated among clinicians ${ }^{3,4}$. Partial or complete lockdowns have imposed reduced healthcare access, leading to a systematic problem in gathering daily medications and attending to medical consultations. Altogether, the increase in total number of cases presenting COVID-19 has changed the prevalence of other common consequences of public health issues, such as myocardial infarction and stroke ${ }^{5}$ reports have indicated decreasing rates of new ischemic stroke diagnoses during the COVID-19 pandemic. The observed decrease in emergency department (ED. Ultimately, public health managers face a challenge in assessing these patients and developing screening strategies to adequately identify them. Another level of care would include a panel of measures to diminish their needs.

Limited access to resources is a major determinant of health outcomes. In the context of a pandemic, these factors have even magnified impact, and they should be addressed accordingly. At the individual level, telehealth strategies such as videocalls and remote consultations have been described as an opportunity to improve mental health in older adults. However, individuals living in low- and middle-income settings usually present low education and difficulty to learn how to handle electronic devices and they also present an important limitation of internet access ${ }^{6}$. Moreover, physical exercise has been recommended by all health professionals, though adherence to regular physical exercising is very limited in these areas ${ }^{7}$. At a populational level, high population density in urban areas associated with large families, sometimes sharing the same bedroom than older adults, increase the spread of COVID and the viral load they have contact with. At a governmental level, financial barriers impair the delivery of care to the elderly population because of overcrowded emergency rooms and limited hospital beds ${ }^{8}$. Ultimately, less adherence to social distancing and understanding of the mechanism of air dispersion of the virus are among the most difficult factors to control in a society that poorly understands the host-disease interaction.

A massive, cognitive behavioral approach may provide important advancements in overcoming prevalent challenges faced by low and middle-income nations. Repeated, inclusive and empathetic measures are essential to support mental healthcare of older adults in this setting (Tab. 1). Alliance between society, public managers and health professionals may be the key to plan the strategies to mitigate the negative effects of the pandemic in older adults. 
Table 1. Proposed strategies to mitigate the negative impact of COVID-19 pandemic in mental health of older adults.

\begin{tabular}{|c|c|}
\hline Individual & $\begin{array}{l}\text { - Stimulating the importance of social distancing and the quarantine. } \\
\text { - Educating about the usage of masks and hand hygiene. } \\
\text { - Providing phone or video calls regularly. } \\
\text { - Teaching Cognitive-behavioral strategies: change of perspective, change of body sensations. } \\
\text { - Stimulating physical exercising regularly. }\end{array}$ \\
\hline Collective & $\begin{array}{l}\text { - Increasing public awareness of COVID severity. } \\
\text { - Implementing healthcare hotlines. } \\
\text { - Orientating when to seek for help. } \\
\text { - Identifying the most vulnerable subpopulations of older adults, such as those with previous } \\
\text { known mental disorder. } \\
\text { - Providing access to essential healthcare and medications. }\end{array}$ \\
\hline
\end{tabular}

\section{References}

1. Armitage R, Nellums LB. COVID-19 and the consequences of isolating the elderly. Lancet Public Health. 2020 May;5(5):e256.

2. Douma L, Steverink N, Hutter I, Meijering L. Exploring Subjective Well-being in Older Age by Using Participantgenerated Word Clouds. The Gerontologist. 2015 Sep 1;gnv119.

3. Serafini G, Bondi E, Locatelli C, Amore M. Aged Patients With Mental Disorders in the COVID-19 Era: The Experience of Northern Italy. Am J Geriatr Psychiatry. 2020 Jul;28(7):794-5.

4. Draper BM. Suicidal behaviour and suicide prevention in later life. Maturitas. 2014 Oct;79(2):179-83.

5. Dula AN, Gealogo Brown G, Aggarwal A, Clark KL. Decrease in Stroke Diagnoses During the COVID-19 Pandemic: Where Did All Our Stroke Patients Go? JMIR Aging. 2020 Oct 21;3(2):e21608.

6. Yang Y, Li W, Zhang Q, Zhang L, Cheung T, Xiang Y-T. Mental health services for older adults in China during the COVID-19 outbreak. Lancet Psychiatry. 2020 Apr;7(4):e19.

7. Landry MD, Van den Bergh G, Hjelle KM, Jalovcic D, Tuntland HK. Betrayal of Trust? The Impact of the COVID-19 Global Pandemic on Older Persons. J Appl Gerontol. 2020 Jul 30;39(7):687-9.

8. Xiang X, Ning Y, Kayser J. The Implications of COVID-19 for the Mental Health Care of Older Adults: Insights from Emergency Department Social Workers. J Gerontol Soc Work. 2020 Jun 16;1-3.

Contribuições: Wyllians Vendramini Borelli - Redação - Preparação do original.

\section{Correspondência}

Wyllians Vendramini Borelli

wborelli@hcpa.edu.br

Submetido em: 08/01/2020

Aceito em: 11/01/2021 